\section{RMD Open}

Rheumatic \&

Musculoskeletal Diseases

\title{
Educational needs of health professionals working in rheumatology in Europe
}

Theodora P M Vliet Vlieland, ${ }^{1}$ Cornelia H.M van den Ende, ${ }^{2}$ Francoise Alliot-Launois, ${ }^{3}$ Catherine Beauvais, ${ }^{4}$ Milena Gobbo, ${ }^{5}$ Annamaria lagnocco, ${ }^{6}$ Ingrid E Lundberg, ${ }^{7}$ Pedro V Munuera-Martínez, ${ }^{8}$ Christina H Opava, ${ }^{9,10}$ Yeliz Prior, ${ }^{11,12}$ Anthony Redmond, ${ }^{13,14}$ Hana Smucrova, ${ }^{15}$ Dieter Wiek ${ }^{16}$

\section{ABSTRACT}

van den Ende CHM, Alliot-Launois $\mathrm{F}$, et al. Educational needs of health professionals working in rheumatology in Europe. RMD Open 2016;2:e000337. doi:10.1136/rmdopen-2016000337

- Prepublication history and additional material is available. To view please visit the journal (http://dx.doi.org/ 10.1136/rmdopen-2016000337)

Received 18 July 2016 Revised 12 October 2016 Accepted 22 October 2016

\section{CrossMark}

For numbered affiliations see end of article.

Correspondence to

Professor Theodora P M Vliet Vlieland; t.p.m.vliet_vlieland@ lumc.nl
Objective: To explore the availability of postgraduate education for health professionals (HPs) working in rheumatology in Europe, and their perceived educational needs and barriers for participation in current educational offerings.

Methods: Structured interviews were conducted with national representatives of rheumatology HPs' organisations and an online survey among individual HPs was disseminated through existing European League Against Rheumatism (EULAR) networks (10 languages including English). These comprised questions on: availability of postgraduate education, familiarity with EULAR and its educational offerings, unmet needs regarding the contents and mode of delivery and potential barriers to participate in education (0-10 scales).

Results: According to 17 national representatives, postgraduate rheumatology education was most common for nurses, physical and occupational therapists. There were 1041 individuals responding to the survey, of whom $48 \%$ completed all questions. More than half $(56 \%)$ were familiar with EULAR as an organisation, whereas $<25 \%$ had attended the EULAR congress or were familiar with EULAR online courses. Educational needs regarding contents were highest for 'inflammatory arthritis' and 'connective tissue diseases' and regarding modes of delivery for 'courses organised in own country' and 'online courses'. Important barriers to participation included lack of 'resources', 'time' and 'English language skills'. Overall, there was considerable variation in needs and barriers among countries.

Conclusions: There is a lack of postgraduate rheumatology education for HPs in most countries. There are opportunities to raise awareness regarding EULAR educational offerings and to develop courses provided in HPs' own country, tailored to national needs and barriers and taking language barriers into consideration.

\section{INTRODUCTION}

One of the key objectives set by the European League Against Rheumatism (EULAR) for 2017 is to "be a pre-eminent
Key messages

What is already known about this subject?

- Health professionals (HPs) working in rheumatology constitute a diverse group, with considerable variation within and between countries regarding their basic training as well as their roles and responsibilities in the diverse healthcare delivery systems.

- Information on the availability and needs regarding education on the postgraduate level for HPs working in rheumatology across Europe is scanty.

What does this study add?

- This study among individual HPs working in rheumatology across Europe and their national representatives shows that, with the exception of nurses, there is a lack of postgraduate rheumatology education for HPs in most countries.

- The educational needs of HPs vary considerably across countries.

- Barriers to take part in educational offerings include, among others, lack of resources and time and limited mastery of English.

- There is considerable interest in online courses, as well as in face-to-face courses, preferably provided in HPs' own country.

How might this impact on clinical practice?

- Patients with rheumatic and musculoskeletal conditions are in need of care provided by knowledgeable and skilled professionals. The availability of adequate postgraduate education contributes, together with work-based supervision and training, to their competencies.

- The development of educational offerings for HPs requires a tailored approach, taking into account the characteristics of national healthcare and education systems as well as known barriers and facilitators for participation.

provider and facilitator of high-quality educational offerings for physicians, health professionals in rheumatology and people with 
rheumatic and musculoskeletal diseases". ${ }^{1}$ The EULAR Standing Committee of Health Professionals (HP) in Rheumatology contributes to this overarching aim by improving and extending educational offerings for nonmedical HPs in rheumatology, in collaboration with the EULAR Standing Committee for Education, ESCET. ${ }^{2}$ For this purpose, an educational subcommittee was instituted, comprising HPs from various professional backgrounds, rheumatologists (one being the chair of ESCET) and a patient representative (chair of the EULAR Standing Committee of PARE).

Non-medical HPs in rheumatology include healthcare providers from various professions, for example, nurses, physical therapists, occupational therapists, psychologists, social workers, dieticians, podiatrists and many other professionals practising in rheumatology. As such, they constitute a diverse group with considerable variation within and between countries for requirements about what constitutes basic training, and its availability, as well as the roles and responsibilities in the diverse healthcare delivery systems. There exists a lack of standardisation for the postgraduate educational requirements for HPs working in rheumatology as well, ${ }^{3}$ in particular at an international level. The situation of HPs is thereby largely different from the education of rheumatologists, where European standards are set for the postgraduate training by the European Union of Medical Specialists. ${ }^{4}$

With respect to rheumatology HPs' educational needs, a survey among 162 rheumatology HPs in the UK demonstrated educational needs in particular regarding the provision of advice on exercise and pain medication and the management of osteoarthritis $(\mathrm{OA}) .^{5}$ In an international survey on care for patients with systemic sclerosis (SSc) among 56 HPs, almost all (98\%) respondents reported having educational needs, with the topics of management of stiffness (67\%), pain $(60 \%)$ and impaired hand function (56\%) in SSc being mentioned most frequently. ${ }^{6}$ In addition, HPs' educational and training needs regarding adolescent health and transitional care in rheumatology were determined, but these studies were performed more than a decade ago. ${ }^{7} 8$

Currently, there are various educational offerings available for HPs working in rheumatology, which are mostly country-specific. Previously, at the national level, the need for the availability of validated rheumatology-based courses has been suggested, combined with structured programmes of work-based supervision and training to ensure consistency of clinical competency and knowledge for all HPs working in rheumatology. ${ }^{9}$ Indeed, in some countries, there are a range of courses available for health professionals, an example being the UK, where the British Health Professionals in Rheumatology organises a number of high calibre educational courses, which are Continuing Professional Development accredited by the Royal College of Physicians (http:// www.rheumatology.org.uk/bhpr/education_and_awards/ bhpr_courses_and_endorsed_courses.aspx; accessed 1 April 2016).
At the international level, in Europe, EULAR offers various courses and bursaries specifically for HPs, but information on familiarity with EULAR and its educational offerings among HPs is lacking. Regarding the participation of young medical professionals working in the field of rheumatology, a survey demonstrated that only a minority had participated in the EULAR postgraduate course. ${ }^{10}$

At present, there is a lack of insight into the availability of postgraduate education for HPs in rheumatology across Europe. There is also a clear gap in knowledge on HPs' educational needs. Taking into account the variety of undergraduate education and scope of practice within and among HPs in different countries, it is clear that the development of appropriate postgraduate educational offerings serving the needs of HPs in multiple countries is not a self-evident endeavour.

So the first and foremost step for the EULAR HP educational subcommittee to take was to obtain a better understanding of the postgraduate education of rheumatology HPs across Europe. The present study therefore aimed (1) to explore the availability of postgraduate education for rheumatology HPs in European countries and (2) to define rheumatology HPs' educational needs and (3) to identify barriers and facilitators for taking part in postgraduate education.

\section{METHODS}

\section{Study design}

The study consisted of interviews among the representatives (eg, presidents, leads) of national HPs in rheumatology organisations, including those not being an official EULAR member and an online survey for individual HPs. The educational subcommittee of the EULAR Standing Committee of HPs in Rheumatology prepared an interview guide and the survey contents following explorative interviews with members. The interviews and the survey were conducted from March 2015 until November 2015.

\section{Interviews of national representatives of HPs in rheumatology}

The educational subcommittee agreed on the following main themes for the interview:

A. Availability of postgraduate education specifically for HPs (either multidisciplinary or discipline-specific);

B. HPs' access to postgraduate education and/or conferences for rheumatologists;

C. Interest into the following educational offerings: face-to-face postgraduate educational courses in English (0-10 scale, ranging from $0=$ no interest to 10 very large interest); a teach-the-teacher module in addition to face-to-face postgraduate education (specific training to enable HPs to disseminate the knowledge and skills from the course within their own country) (yes/no), and active promotion of an online course for HPs (yes/no); and 
D. Rating of eight barriers for HPs in their country to participate in educational offerings (0-10 scale, ranging from $0=$ no barrier to $10=$ a very large barrier).

National presidents or representatives were invited by email. Members of the subcommittee, who were all actively involved in the development of the content, conducted the interviews by telephone or in person.

\section{Online survey among individual HPs}

The topics for the online survey for individual HPs were similar to those in the interviews for national representatives, with the exception of individual HPs being additionally asked about:

E. Their familiarity with EULAR, the EULAR Standing Committee of HPs, the EULAR website and EULAR educational offerings; and

F. Their needs for 12 specific topics to be addressed in educational offerings $(0-10$ scale, ranging from $0=$ no need to $10=$ a very large need).

An electronic version of the survey was made using NetQuestionnaires Nederland B.V. (Amsterdam, the Netherlands). With this system, responses from one computer's IP (Internet Protocol) address can only be submitted once. The access information for the online survey was circulated to national representatives of rheumatology HPs' organisations for dissemination among members and other contacts, to individual HPs who had once visited the EULAR annual congress, and was announced on the EULAR website and the EULAR Health Professionals' newsletter. After the English version of the survey was online, with the help of subcommittee members and liaison persons, translations were made into Czech, Danish, French, German, Italian, Portuguese, Spanish, Swedish and Turkish, and with the access information to the translated surveys being circulated among relevant national representatives. Given this method of recruitment, no reminders to individuals were sent; however, national presidents or contact persons were each reminded at least once to bring the invitation under the attention of HPs working in rheumatology in their country. Owing to a logistic error, the UK national president was contacted for the first time with the request to disseminate the survey only in September 2015.

\section{Analyses}

Descriptive statistics were used for the results of the interviews (numbers and median and ranges, where appropriate). The survey was analysed anonymously, using descriptive analyses (numbers and proportions, and means and SD or median and range, where appropriate). Since the survey was disseminated to reach out to HPs in $>25$ countries, a relatively low response rate in some individual countries was to be expected. Therefore, a geographical categorisation was made into three groups: north/western European (Austria, Belgium, Denmark, Germany, France, Ireland, the Netherlands, Norway, Sweden, Switzerland, UK), southern European (Italy, Portugal, Spain, Malta, Greece) and eastern European countries (Bulgaria, Czech Republic, Hungary, Lithuania, Poland, Romania, Russia, Serbia, Slovenia, Turkey). The characteristics of responders who completed the survey completely or in part were done by means of unpaired t-test, Mann-Whitney $\mathrm{U}$ test or $\chi^{2}$ test, where appropriate. Comparisons of needs and barriers scores among the three categories of countries, individual countries and professions with the largest numbers of responders were carried out by analysis of variance, with post hoc analysis and Bonferroni correction for multiple comparisons.

Regarding the rating of the importance of the barrier 'English Language', analyses were peprformed separately for the non-English version. For all other analyses, the results of the English and translated versions of the survey were combined.

All analyses were carried out using STATA V.13 (StataCorp LP, Texas, USA).

\section{RESULTS}

\section{Interviews}

Twenty national presidents of rheumatology HP organisations and/or other national contact persons, representing 17 countries (Austria, Belgium, Czech Republic, Denmark, Germany, France, Hungary, Ireland, the Netherlands, Norway, Portugal, Russian Federation, Spain, Sweden, Switzerland, Turkey, UK), responded positively to the invitation for a (telephone) interview.

Table 1 shows the availability of postgraduate education in rheumatology for HPs in 17 countries. Overall, postgraduate rheumatology education for nurses was available in 13 countries, for physical therapists in 8 countries and for occupational therapists in 7 countries, whereas in only 3 or less countries postgraduate

Table 1 Availability of postgraduate education in rheumatology for HPs at the national level in 17 countries* $^{*}$

Multidisciplinary postgraduate education specifically 8 for HPs

Monodisciplinary postgraduate HP education

Nurses

Physical therapist

Occupational therapists

Psychologists

Podiatrists

Social workers

Dieticians

Physician assistants

Rheumatologists' courses open for HPs

Multidisciplinary rheumatology conferences

addressing HP care

Figures represent number of countries.

*Based on interviews with representatives from Austria, Belgium, Czech Republic, Denmark, Germany, France, Hungary, Ireland,

the Netherlands, Norway, Portugal, Russian Federation, Spain,

Sweden, Switzerland, Turkey, UK.

HPs, health professionals. 
rheumatology education for professionals from other disciplines (eg, podiatrists, social workers) was available.

The median score for estimated potential interest in face-to-face postgraduate educational courses in English was 5.0 (range 4.0-7.0) for courses adjacent to the annual congress, 6.5 (range 5.0-8.0) for such courses to be organised in an easily accessible European city and 6.0 (5.0-10.0) for such a course in their own country. Regarding the latter, some respondents expressed the need for such a course to be in their own language $(n=6)$ or organised in connection with a national meeting $(\mathrm{n}=1)$.

Representatives from 11 countries expressed an interest in a teach-the-teacher module in addition to face-to-face postgraduate education, and all 17 were interested to promote an online course for HPs.

Regarding anticipated barriers for HPs to participate in educational offerings, the median rating was highest (>6) for resources (9.5, range 3-10), the English language (8.0, range $2-10$, the UK and Ireland excluded) and lack of accreditation at the national level (7.0, range $0-10)$. The median rating was 4-6 for lack of support from colleagues or staff $(5.0$, range $0-10)$ and potential mismatch between educational needs and offerings (4.0, range $0-7$ ), whereas the median rating was $<4$ for lack of information on educational offerings (2.5, range $0-3)$, lack of time (3.5, range $0-8)$ or lack of anticipated benefits $(2.0$, range $0-6)$.

\section{Survey}

In total, there were 1060 responders to the survey, of whom 19 were from a non-European continent (eg, Canada, Morocco, Mexico and Peru). The 1041 responders from Europe were from 26 different countries (Austria $n=3$, Belgium $n=28$, Bulgaria $n=1$, Czech Republic $n=36$, Denmark $n=65$, Germany $n=82$, Greece $\mathrm{n}=1$, France $\mathrm{n}=163$, Hungary $\mathrm{n}=1$, Ireland $\mathrm{n}=12$, Italy $\mathrm{n}=142$, Lettonia $\mathrm{n}=1$, Lithuania $\mathrm{n}=1$, Malta $\mathrm{n}=1$, the Netherlands $n=66$, Norway $n=33$, Poland $n=1$, Portugal $\mathrm{n}=17$, Serbia $\mathrm{n}=2$, Slovenia $\mathrm{n}=1$, Romania $\mathrm{n}=5$, Spain $n=261$, Sweden $n=37$, Switzerland $n=75$, Turkey $n=2$, UK $\mathrm{n}=4)$.

Of the 1041 responders, 217 completed the English version $(21 \%)$, whereas the percentages (numbers) using 1 of the translated versions were: Czech 3\% $(\mathrm{n}=34)$, Danish 5\% (n=53), French 16\% ( $\mathrm{n}=168)$, German 12\% ( $\mathrm{n}=122)$, Italian 13\% ( $\mathrm{n}=140)$, Portuguese $2 \%(\mathrm{n}=17)$, Spanish 25\% ( $\mathrm{n}=259)$, Swedish $3 \% \quad(\mathrm{n}=30)$ and Turkish $0.1 \%(\mathrm{n}=1)$ (figure 1$)$.

Table 2 shows the characteristics of the 1041 responders, of whom $48 \% \quad(n=500)$ completed the entire survey. Completers of the survey were slightly yet statistically significantly older (mean 42 (SD 11) versus 41 (SD 12) years; $p=0.04$ ) and more often from a north/western country than non-completers (68\% vs $42 \%$; $\mathrm{p}<0.001)$, whereas there were no differences regarding proportions of female responders ( $85 \%$ vs $87 \%$ female; $\mathrm{p}=0.548$ ). Among responding nurses, the proportion of completers was higher (53\%) than that among physical and occupational therapists $(45 \%$ and $44 \%)(p=0.051$; see online supplementary table A).

Most responders were from north/western and southern Europe, whereas only 5\% were from eastern Europe. Nurses, physical therapists and occupational therapists constituted the majority of the responders. About half of the responders were working in a hospital as opposed

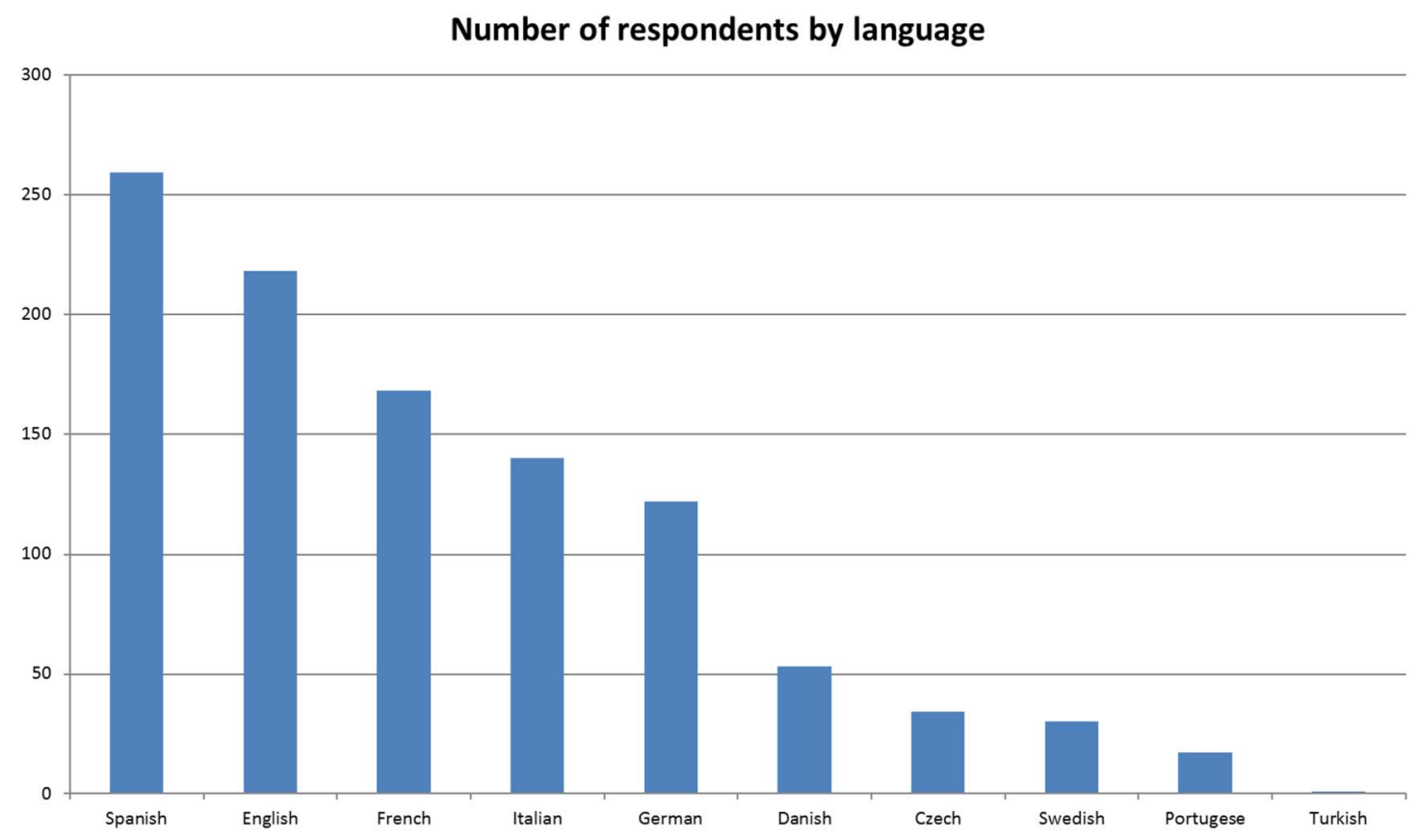

Figure 1 Number of health professionals working in rheumatology responding to various language versions of an online survey on educational needs. 
Table 2 Characteristics of individual respondents to an online survey among European health professionals working in rheumatology $(\mathrm{N}=1041)$

\begin{tabular}{|c|c|}
\hline Age, years, mean (SD) & $41(11)$ \\
\hline Female, $\mathrm{N}(\%)$ & $897(86)$ \\
\hline \multicolumn{2}{|l|}{ European region } \\
\hline North/western Europe & $568(55)$ \\
\hline Eastern Europe & $52(5)$ \\
\hline Southern Europe & $421(40)$ \\
\hline \multicolumn{2}{|l|}{ Profession, $\mathrm{N}(\%)^{\star}$} \\
\hline Nurse $†$ & $415(39)$ \\
\hline Physical therapist & $294(27)$ \\
\hline Occupational therapist & $127(12)$ \\
\hline Podiatrist & $49(5)$ \\
\hline Physician assistant & $47(4)$ \\
\hline Social worker & $20(2)$ \\
\hline Psychologist & $19(2)$ \\
\hline Dietician & $14(1)$ \\
\hline Other & $87(8)$ \\
\hline \multicolumn{2}{|l|}{ Qualification/academic title $(n=974)$} \\
\hline $\begin{array}{l}\text { Certificate/diploma not equalling a bachelor" } \\
\text { degree }\end{array}$ & $323(33)$ \\
\hline Bachelor's degree or similar & $346(35)$ \\
\hline Master's degree & 209 (22) \\
\hline $\mathrm{PhD}$ & $81(8)$ \\
\hline Professorship & $15(2)$ \\
\hline Postgraduate education, yes, N (\%) & $397(40)$ \\
\hline If yes $(\mathrm{N}=397)$, received accreditation? & $186(49)$ \\
\hline \multicolumn{2}{|l|}{ Working situation* ${ }^{*}$} \\
\hline General hospital & $264(25)$ \\
\hline Academic hospital & $295(28)$ \\
\hline Private practice/primary care & $257(25)$ \\
\hline Rehabilitation centre & 79 (8) \\
\hline University of professional education & $60(6)$ \\
\hline University & $58(5)$ \\
\hline Other & $173(17)$ \\
\hline Working experience, years, mean (SD) & $11(9)$ \\
\hline Working with patients in the past year $\mathrm{N}(\%)$ & $869(82)$ \\
\hline \multicolumn{2}{|l|}{ If yes, } \\
\hline $0-4$ patients per week & $92(11)$ \\
\hline 2-5 patients per week & $202(24)$ \\
\hline 6-20 patients per week & $268(32)$ \\
\hline$>20$ patients per week & 269 (32) \\
\hline
\end{tabular}

*Multiple answers possible, 1072 professions.

†Including clinical nurse specialist, nurse practitioner.

to, for example, working in primary care or being an academic, and the majority had been seeing patients with rheumatic and musculoskeletal diseases in the past year.

The academic qualification or title of the responders was at the Bachelor's level or higher in about two-thirds of the cases, whereas 22\% $(n=209)$ had a Master's degree and $10 \%(\mathrm{n}=96)$ a $\mathrm{PhD}$ and/or attained a professorship. A total of $40 \%(n=397)$ had taken part in postgraduate education.

Regarding the familiarity with EULAR, 56\% ( $\mathrm{n}=545)$ reported being familiar with EULAR, $42 \%(n=410)$ with the EULAR website, $28 \%(\mathrm{n}=274)$ were familiar with the EULAR Standing Committee of HPs and 23\% ( $n=228)$ with the HP newsletter. Regarding EULAR educational offerings, $21 \%$ (201) previously participated in the EULAR congress, and $14 \%(\mathrm{n}=137)$ were familiar with EULAR online courses.

Table 3 shows the HPs' needs regarding the contents and delivery of educational offerings. For general aspects, in the total group the need was the highest for non-pharmacological treatment (mean 6.0 SD 2.8). For disease-specific contents, the highest needs concerned inflammatory arthritis (mean 6.5 SD 2.8) and connective tissue diseases (mean 6.5 SD 2.7).

Concerning the mode of delivery, the highest mean score was for an online course (5.7 SD 3.2). With respect to the delivery of face-to-face courses, the highest need score concerned a course provided in the respondent's own country. The need scores for monodisciplinary or multidisciplinary courses (either or not with rheumatologists) were similar.

Table 3 shows that the educational needs were overall higher in southern European countries than in north/ western and eastern European countries. Except for the preference ratings of face-to-face courses, online courses, all three aspects of preferred location and the provision of courses for HPs from one's own discipline, all differences between respondents from southern Europe were statistically significantly different from those from north/western countries or both.

A comparison of the educational needs of HPs among the three countries with the largest numbers of respondents (Spain, Italy and France) showed that there was also variation among countries. For all items related to the contents of education, the need scores of French responders were significantly lower than those of Italian or Spanish responders (see online supplementary table B).

In addition, regarding the comparison among the professions with the highest numbers of responders, nurses had higher educational needs scores regarding pharmacological treatment than physical and occupational therapists. Moreover, nurses had lower educational need scores in comparison with physical therapists for inflammatory arthritis, OA, fibromyalgia and low back pain. Nurses and physical therapists had higher educational scores than occupational therapists regarding the topics diagnostics and epidemiology (see online supplementary file table $\mathrm{C}$ ).

Table 4 shows the ratings of HPs regarding anticipated barriers for participation in education. The most important barriers in the total group included a lack of resources (7.2 SD 2.8), time (5.8 SD 2.9) and English language skills (5.8 SD 3.4). In the total group of responders, the mean score for the English language skills was 5.0 (SD 3.6). Overall, the anticipated barrier scores were highest in respondents from southern European countries, with all differences with respondents from north/western and eastern European countries reaching statistical significance.

Regarding the comparison among respondents from France, Italy and Spain, the scores for the barriers lack of support, mismatch between offerings and needs and 
Table 3 Health professionals' educational needs regarding general topics and diseases and preferred mode of delivery (scored on a scale from 0 to 10) by European region, based on an online survey (all values represent mean (SD).

\begin{tabular}{|c|c|c|c|c|}
\hline & $\begin{array}{l}\text { North/western } \\
\text { Europe }(\mathrm{N}=413)\end{array}$ & $\begin{array}{l}\text { Eastern Europe } \\
(n=30)\end{array}$ & $\begin{array}{l}\text { Southern Europe } \\
(\mathrm{N}=193)\end{array}$ & $\begin{array}{l}\text { Total } \\
(\mathrm{N}=636)\end{array}$ \\
\hline \multicolumn{5}{|l|}{ General aspects of management } \\
\hline Non-pharmacological treatment & $5.8(2.6)$ & $5.5(2.9)$ & $6.7(2.9)^{\star}$ & $6.0(2.8)$ \\
\hline Pharmacological treatment & $4.9(2.8)$ & $5.3(2.6)$ & $6.4(2.7)^{\star}$ & $5.4(2.8)$ \\
\hline Diagnostic assessment & $4.7(3.0)$ & $4.7(2.9)$ & $6.9(2.8) \dagger$ & $5.3(3.1)$ \\
\hline Practice organisation & $4.4(2.8)$ & $5.6(3.0)$ & $6.3(2.7)^{\star}$ & $5.0(2.9)$ \\
\hline Epidemiology & $5.1(2.6)$ & $4.8(2.7)$ & $6.1(2.7) \dagger$ & $5.4(2.7)$ \\
\hline Teach the teacher & $4.8(3.1)$ & $5.7(3.4)$ & $6.6(3.1)^{\star}$ & $5.4(3.2)$ \\
\hline \multicolumn{5}{|l|}{ Rheumatic diseases to be addressed } \\
\hline Inflammatory arthritis & $6.0(2.8)$ & $6.6(3.4)$ & $7.6(2.3)^{\star}$ & $6.5(2.8)$ \\
\hline Osteoarthritis & $5.6(2.7)$ & $6.0(3.0)$ & $7.6(2.4) \dagger$ & $6.2(2.8)$ \\
\hline Connective tissue diseases & $6.1(2.6)$ & $6.5(3.2)$ & $7.4(2.4)^{\star}$ & $6.5(2.7)$ \\
\hline Fibromyalgia & $5.7(2.9)$ & $5.7(2.7)$ & $7.8(2.3) \dagger$ & $6.3(2.9)$ \\
\hline Low back pain & $5.3(2.5)$ & $5.9(2.7)$ & $7.6(2.5) \dagger$ & $6.0(2.9)$ \\
\hline Osteoporosis & $5.6(2.7)$ & $5.9(3.1)$ & $7.2(2.7) \dagger$ & $6.1(2.8)$ \\
\hline \multicolumn{5}{|l|}{ Preferred mode of delivery } \\
\hline Face-to-face course & $4.5(3.2)$ & $4.2(3.9)$ & $5.1(3.3)$ & $4.6(3.2)$ \\
\hline $\begin{array}{l}\text { Face-to-face course with } \\
\text { teach-the-teacher module }\end{array}$ & $4.0(3.0)$ & $4.5(3.6)$ & $5.1(3.4)^{\star}$ & $4.3(3.2)$ \\
\hline Practical workshop & $4.2(3.3)$ & $5.9(3.9)$ & $6.2(3.4)^{\star}$ & $4.7(3.4)$ \\
\hline Online course & $5.5(3.1)$ & $5.4(3.5)$ & $5.7(3.5)$ & $5.7(3.2)$ \\
\hline \multicolumn{5}{|l|}{ Preferred location of face-to-face course } \\
\hline Adjacent to EULAR Congress & $3.9(3.1)$ & $3.9(3.7)$ & $4.6(3.3)$ & $4.1(3.2)$ \\
\hline Easily accessible European city & $4.0(3.0)$ & 4.9 (3.9) & $4.7(3.5)$ & $4.2(3.2)$ \\
\hline Own country & $5.5(3.4)$ & $6.5(3.8)$ & $6.0(3.6)$ & $5.7(3.5)$ \\
\hline \multicolumn{5}{|l|}{ Composition of participants } \\
\hline HPs $\ddagger$ from own discipline & $5.9(3.0)$ & $5.8(3.5)$ & $6.6(2.9)^{*}$ & $6.1(3.0)$ \\
\hline HPs from multiple disciplines & $5.7(2.8)$ & $5.8(3.4)$ & $7.1(2.6)^{*}$ & $6.1(2.8)$ \\
\hline $\begin{array}{l}\text { HPs from multiple disciplines including } \\
\text { rheumatologists }\end{array}$ & $6.0(2.9)$ & $6.6(3.1)$ & $7.2(2.6)^{*}$ & $6.3(2.9)$ \\
\hline
\end{tabular}

Table 4 Importance of barriers regarding educational offerings by EULAR as perceived by health professionals working in rheumatology, based on an online survey (all values represent mean (SD)

\begin{tabular}{|c|c|c|c|c|}
\hline & $\begin{array}{l}\text { North/western } \\
\text { Europe }(\mathrm{N}=341)\end{array}$ & $\begin{array}{l}\text { Eastern Europe } \\
(\mathrm{n}=23)\end{array}$ & $\begin{array}{l}\text { Southern Europe } \\
(\mathrm{N}=136)\end{array}$ & $\begin{array}{l}\text { Total } \\
(\mathrm{N}=500)\end{array}$ \\
\hline Lack of resources to cover costs & $7.0(2.9)$ & $6.4(3.2)$ & $8.0(2.4)^{*}$ & $7.2(2.8$ \\
\hline $\begin{array}{l}\text { Lack of support from colleagues, } \\
\text { rheumatologists and/or managerial staff }\end{array}$ & $3.7(3.1)$ & $4.0(3.4)$ & $6.0(3.0)^{*}$ & $4.3(3.2$ \\
\hline Lack of mastery of English $(n=372)$ & $5.5(3.6)$ & $5.3(3.4)$ & $6.3(3.1)^{\star}$ & $5.8(3.4$ \\
\hline $\begin{array}{l}\text { Mismatch between contents offered and own } \\
\text { educational needs }\end{array}$ & $3.9(2.6)$ & $2.7(2.1)$ & $5.4(2.7)^{*}$ & $4.3(2.7$ \\
\hline $\begin{array}{l}\text { Lack of information on EULAR educational } \\
\text { offerings for HPs }\end{array}$ & $5.4(2.9)$ & $4.4(2.9)$ & $6.2(2.9)^{\star}$ & $5.5(2.9$ \\
\hline Lack of time it takes to participate & $5.5(2.9)$ & $4.5(3.6)$ & $6.5(2.8)^{*}$ & $5.8(2.9$ \\
\hline $\begin{array}{l}\text { Lack of accreditation by national professional } \\
\text { organisation }\end{array}$ & $3.9(3.0)$ & $3.0(2.9)$ & $5.5(3.1)^{*}$ & $4.3(3.1)$ \\
\hline Having low expectations of benefit & $2.6(2.4)$ & $2.3(2.6)$ & $4.3(2.8)^{\star}$ & $3.1(2.6$ \\
\hline
\end{tabular}


having low expectations were lower in French respondents than in respondents from Italy and/or Spain (see online supplemental file table D). Anticipated barriers were quite similar among nurses, physical and occupational therapists, with only the score for mastery of English being significantly lower in physical therapists than in nurses or occupational therapists (see online supplementary file table E).

\section{DISCUSSION}

This study among national representatives of rheumatology HPs and individual HPs across European countries found that, with the exception of nurses, there is a lack of postgraduate rheumatology education for HPs in most countries. There are opportunities to raise familiarity with EULAR educational offerings, with considerable interest in online courses such as the EULAR HP Online course and face-to-face courses provided in HPs' own country. Relevant aspects to be taken into account in order to plan a future curriculum are, among others, lack of resources and time and limited mastery of English.

Although in some European (eg, the UK) and non-European countries (eg, the USA) postgraduate education for HPs in rheumatology is available, there was a lack of insight into educational offering among European countries at large. Our inventory among national HP representatives makes it clear that in many countries there is a shortage of educational offerings at the postgraduate level, with the exception of education for nurses.

Overall, the variability regarding educational needs was large, with overall educational needs being highest in southern European countries. It remains to be established whether the high response numbers from some southern European countries is a reflection of high educational needs as well. Nevertheless, our findings suggest that with future educational offerings, in particular the needs and preferences of HPs in these countries should be taken into account. There may also be differences among individual countries, as was illustrated by a comparison of the results from France, Italy and Spain.

Concerning preferences for the contents of education, our survey among individual HPs overall demonstrated the highest needs for non-pharmacological treatment, inflammatory arthritis and connective tissue diseases. No similar inventories are available for comparison; however, the need regarding connective tissue diseases is in line with the results of a survey on defined educational needs among HPs regarding the treatment of scleroderma. ${ }^{6}$ Another survey concerned HP educational needs on adolescent health and transitional care, ${ }^{7}$ an area that was not specifically included in our survey. Moreover, in undergraduate education for nurses, physical therapists and occupational therapists in the UK, limitations in key areas were identified. ${ }^{11}$ Based on these gaps, a core set of topics was defined. ${ }^{12}$

Given the large variation in the scope of practice of HPs in rheumatology among countries, international educational offerings should preferably focus on the organisation of educational courses at the postgraduate level. There may, however, be large variation regarding the basic education of HPs with the same profession across countries. This variety should be taken into account with the development of educational offerings at the postgraduate level. Regarding the mode of delivery, the interest in online provision of education was high. This finding is in line with results from the aforementioned study on undergraduate rheumatology education. ${ }^{12}$ In that study, innovative delivery methods were proposed, with collaboration between educationalists, clinicians and patients being strongly recommended. Apart from e-learning, the use of clinical videos and interactive games was among the suggestions. Moreover, education should ideally consist of a combination of courses addressing knowledge and skills and training on the spot. Previously, at the national (UK) level, the availability of a validated rheumatology-based course, combined with a structured programme of work-based supervision and training to ensure consistency of clinical competency and knowledge for all HPs working in rheumatology has been suggested..$^{9}$

A number of barriers for HPs to participate in postgraduate education were identified in this study, with lack of time and money being most prominent. Apart from the general need to better underscore the benefits of properly trained HPs for the quality of care for people with RMDs, offering postgraduate education in such a way that time and financial constraints are minimised is needed. The EULAR online course for HPs appears to fulfil these requirements, with indeed the interest among HPs in our survey being substantial. The ratings were found to vary among regions and countries, underlining the need for a tailored approach. Finally, although there were differences among professions, the English language appeared to be a major barrier to participate in educational offerings for many HPs. The fact that the majority of respondents completed the translated versions of our survey confirms that language is an important aspect. Even in North-European countries, where fluency in English is supposed to be common, the majority of HPs completed the survey in their mother tongue. Potential solutions include translations of educational materials and/or working with subtitles, yet all of these require resources and a system to monitor the quality of translations and provide timely updates. Finally, although less frequently mentioned by responders, the way to promote accreditation by national professional bodies should also be considered.

This study had a number of limitations. First, although the absolute number of respondents was substantial, it remains unclear to what extent the results are generalisable to all HPs working in rheumatology in European countries. Since multiple channels were used to get to as many HPs as possible, it cannot be established how many HPs received the invitation, so the response rate cannot be determined. There is a great variety regarding 
the number of responses across countries. The possible explanations for the relatively low response rates in some countries remain unclear, except for the UK where the national president was directly contacted about the active dissemination of the survey relatively late in the process.

Thereby, it could be argued that the perspective of HPs from some countries was either over-represented or under-represented. Finally, the response to the survey was incomplete in a considerable number of cases, with relatively fewer people from southern and eastern European countries completing it. This is most likely due to its length, as the response rate per question gradually declined towards the end of the survey, but may have led to under-representation of the perception of HPs from southern and eastern European countries regarding educational needs and barriers. However, overall, the results were fairly consistent, while at the same time by the division of countries in northern, southern and eastern European countries some differences across European regions could be identified. This categorisation is, however, open to debate, as characteristics of the educational and healthcare systems and cultures may indeed differ largely across countries in different regions of Europe, but are likely to be determined by other factors than geographical orientation alone. Regarding basic (undergraduate) education and training of HPs in different countries, there are European regulations; ${ }^{13}$ yet there is considerable variety, which may have an impact on educational needs and perceived barriers regarding postgraduate education in the field of rheumatology.

Despite these shortcomings, the methodology employed, being a combination of interviews with national representatives and a survey among individual HPs, strengthens the validity of the findings. Another strength of the study was that relatively many HPs who were not familiar with EULAR were identified, limiting the chance of selection bias.

In conclusion, HPs' interest in education is large, with ample opportunities to implement and/or adjust existing offerings to better suit their needs. In addition, novel initiatives including practical skills training and making more use of innovative ways to provide education via the internet are promising, yet barriers in using the English language need to be taken into account. Finally, apart from education at the group level, individual counselling or training is indispensable in the career of a rheumatology HP. Therefore, the importance of mentoring has been articulated for young rheumatologists, ${ }^{14}$ as well as for rheumatology HPs. ${ }^{15}$

\footnotetext{
Author affiliations

${ }^{1}$ Department of Orthopaedics, Rehabilitation and Physical Therapy, Leiden University Medical Center, Leiden, The Netherlands

${ }^{2}$ Department of Rheumatology, Sint Maartenskliniek, Nijmegen, The Netherlands

${ }^{3}$ Department of Rehabilitation, Siege Assistance Publique, Paris, France

${ }^{4}$ Department of Rheumatology, Saint Antoine Hospital, Assistance Publique Hôpitaux de Paris, Paris, France
}

${ }^{5}$ Positivamente Psicólogos, Madrid, Spain

${ }^{6}$ Rheumatology Unit, Sapienza Università di Roma, Rome, Italy

${ }^{7}$ Rheumatology Unit, Department of Medicine, Karolinska University Hospital,

Solna, Karolinska Institutet, Stockholm, Sweden

${ }^{8}$ Department of Podiatry, University of Seville, Seville, Spain

${ }^{9}$ Department of Neurobiology, Care Sciences and Society, Division of

Physiotherapy, Karolinska Institutet, Huddinge, Sweden

${ }^{10}$ Rheumatology Unit, Karolinska University Hospital, Stockholm, Sweden

${ }^{11}$ Centre for Health Sciences Research, University of Salford, Greater

Manchester, UK

${ }^{12}$ East Cheshire NHS Trust, Leighton Hospital, UK

${ }^{13}$ Department of Clinical Biomechanics and Physical Medicine, Leeds Institute of Rheumatic and Musculoskeletal Medicine, Leeds, UK

${ }^{14}$ Leeds NIHR Biomedical Research Unit, Leeds, UK

${ }^{15}$ Department of Rehabilitation, Institute of Rheumatology, Prague, Czech Republic

${ }^{16}$ Deutsche Rheuma-Liga Bundesverband, Bonn, Germany

Acknowledgements The authors are indebted to all national presidents of rheumatology HP organisations or national contact persons taking part in the interviews and to Li Alemo Munters, Jana Korandova, Tiziana Nava, Jan Zernicke, Annette Ladefoged de Thurah, Ricardo Ferreira and others for their help with translations and distribution of the survey and to Nienke Cuperus for developing the electronic versions of the survey. The authors thank all the health professionals who completed the survey.

Contributors CB, MG, PVM-M, YP, HS and DW were involved in the translations and the distribution of the survey. TPMVV and CHMvdE performed the data analysis and wrote the manuscript. All authors were involved in the study design. All authors read and approved the manuscript.

Funding EULAR financially supported a meeting of the authors with the aim of developing the study protocol and the survey.

\section{Competing interests None declared}

Ethics approval The survey employed in this study concerned a once-only and anonymous electronic questionnaire for health professionals. Since they were fully free to either respond or not, no ethical approval was needed. The interview data could not be gathered anonymously; these are, however, reported in such a way that the information cannot be connected to a specific country or person. The study was conducted in accordance with the guidelines for Good Research Practice of the WHO (WHO (2002). Handbook for good clinical research practice (GCP) Guidance for implementation. http:/ apps.who.int/prequal/info_general/documents/GCP/gcp1.pdf).

Provenance and peer review Not commissioned; externally peer reviewed.

Data sharing statement Raw data from this study are available through the corresponding author.

Open Access This is an Open Access article distributed in accordance with the Creative Commons Attribution Non Commercial (CC BY-NC 4.0) license, which permits others to distribute, remix, adapt, build upon this work noncommercially, and license their derivative works on different terms, provided the original work is properly cited and the use is non-commercial. See: http:// creativecommons.org/licenses/by-nc/4.0/

\section{REFERENCES}

1. http://www.eular.org/myUploadData/files/2017\%20objectives $\%$ 20website.pdf (accessed 7 Mar 2016).

2. http://www.eular.org/standing_committees.cfm (accessed 7 Mar 2016).

3. Beauvais C, Gossec L, Mulliez A et al. What competencies for rheumatology nurses? Results of a multicentric survey among health professionals and nurses in France. Ann Rheum Dis 2015;74:1326-7.

4. http://www.eular.org/myUploadData/files/European-TrainingRequirements-in-Rheumatology\%20endorsed\%20UEMS\%20April\% 2012\%202014.pdf (accessed 7 Mar 2016).

5. Lillie K, Ryan S, Adams J. The educational needs of nurses and allied healthcare professionals caring for people with arthritis: results from a cross-sectional survey. Musculoskelet Care 2013;11:93-8. 
6. Willems LM, Redmond AC, Stamm TA, et al. Content of non-pharmacological care for systemic sclerosis and educational needs of European health professionals: a EUSHNet survey. Clin Exp Rheumatol 2015;33(Suppl 91):S153-9.

7. McDonagh JE, Southwood TR, Shaw KL., on behalf of the British Paediatric Rheumatology Group. Unmet education and training needs of rheumatology health professionals in adolescent health and transitional care. Rheumatology (Oxford) 2004;43: 737-43.

8. McDonagh JE, Minnaar G, Kelly K, et al. Unmet education and training needs in adolescent health of health professionals in a UK children's hospital. Acta Paediatr 2006;95:715-19.

9. Carr A. Defining the extended role for allied health professionals in rheumatology. ARC Conference Proceedings No: 12. Chesterfield: Arthritis Research Campaign, 2001.

10. Gaujoux-Viala C, Knevel R, Mandl P, et al. Who are the young professionals working in the field of rheumatology in Europe and what are their needs? An EMEUNET (Emerging EUlar NETwork) survey. Ann Rheum Dis 2012;71:1432-3.
11. Almeida C, Clarke B, O'Brien A, et al. Current provision of rheumatology education for undergraduate nursing, occupational therapy and physiotherapy students in the UK. Rheumatology (Oxford) 2006:45:868-73.

12. Hewlett S, Clarke B, O'Brien A, et al. Rheumatology education for undergraduate nursing, physiotherapy and occupational therapy students in the UK: standards, challenges and solutions. Rheumatology (Oxford) 2008;47:1025-30.

13. http://ec.europa.eu/growth/tools-databases/regprof/index.cfm?action= professions \&profession=podiatrist\&quid=2\&mode=desc\#bottom (accessed 23 Aug 2016).

14. Frank-Bertoncelj M, Hatemi G, Ospelt C, et al. Mentoring of young professionals in the field of rheumatology in Europe: results from an EMerging EUlar NETwork (EMEUNET) survey. Clin Exp Rheumatol 2014;32:935-41.

15. Adams J, Geenen R, Moe RH, et al. Development of the role and scope of an academic mentorship network for health professionals working with people with rheumatological and musculoskeletal conditions across Europe. Musculoskeletal Care 2016;14:126-30. 